\title{
Corpo estranho em Fundo Gástrico com três MESES de EVOLUÇão
}
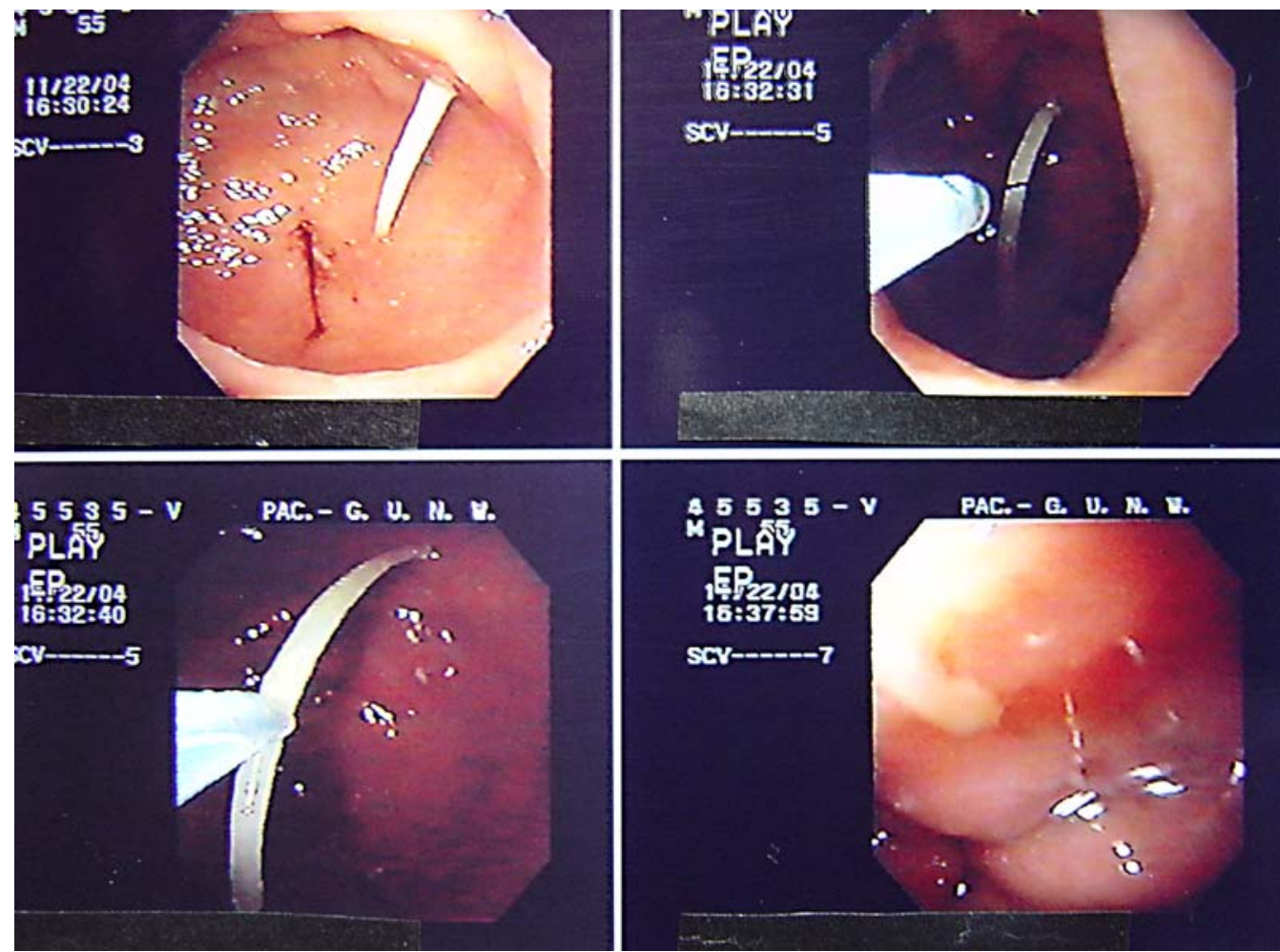

Homem, 55 anos, queixa-se de dor abdominal em cólica há três meses, com aumento importante da sua intensidade nos dois últimos dias. A dor piorava com alimentação e movimentação. Não melhorava com uso de opióides. Como antecedentes, tinha realizado uma intervenção cirúrgica no calcâneo esquerdo há dois meses e desde então estava em uso de antiinflamatórios. Sem história de colecistopatia prévia. RX de tórax e abdominal sem alterações. ECG sem alterações isquêmicas. Resultados laboratoriais mostraram: Hemograma completo: sem alterações. Amilase: 156 U/L (VR: 0,0-90,0 U/L); CK-total: 24 U/L (VR: 24- 195 U/L); CK-MB: I I U/L (VR: 0-25 U/L); Glicemia: 89 mg/dL (VR: 70-99 mg/dL); Triglicérides: 58 mg/dL (VR: < $150 \mathrm{mg} / \mathrm{dL}) ;$ TGO: 9 U/L (VR: $5-38$ U/L); TGP: 22 U/L (VR: 10-40 U/L); FA: 132 U/L (VR: 98-279 U/L); GGT: 45 U/L (VR: I2-45 U/L); Bilirrubina total: 0,4I; Lipase: $10 \mathrm{U} / \mathrm{L}(\mathrm{VR}: 2-15 \mathrm{U} / \mathrm{L})$; LDH: $264 \mathrm{U} / \mathrm{L}$ (VR: 200-480 U/L).

Paciente foi submetido à endoscopia digestiva alta que mostrou na região antral pregueado edemaciado, apresentando corpo estranho (espinha de peixe), com perfuração de suas paredes anterior e posterior, que foi retirado por via endoscópica e apresentou pequena quantidade de secreção purulenta nos orifícios, posterior e anterior e que drenou após a sua retirada. $\bigcirc$ paciente, então, relatou que sua última refeição contendo peixe ocorrera há três meses. Após dois dias de observação, o paciente apresentou melhora do quadro clínico e das queixas álgicas, tendo recebido alta hospitalar.

\section{Guilherme Moreira Borges Araujo, José Luiz Fernandes de Carvalho, Wilson Rodrigues Souza}

\section{Hospital Belo Horizonte- Belo Horizonte- MG}

Referência

I - Magalhães AF, Cordeiro FT, Quilici FA, Machado G, Amarante HMBS, Prolla JC, et al. Endoscopia digestiva diagnóstica e terapêutica. Ia ed.

Rio de Janeiro: Ed. Revinter;2005. 